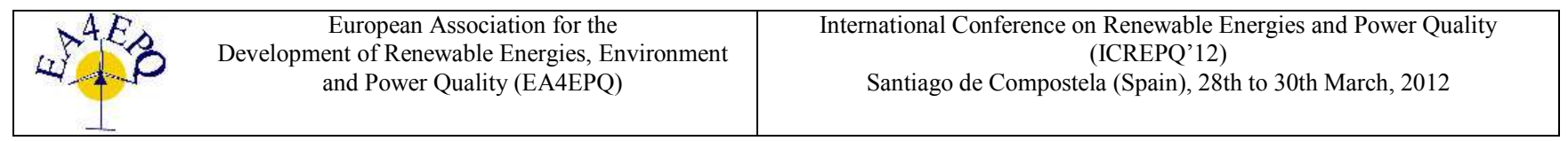

\title{
Study of an Outer-Rotor PMSG for use in Small Wind Applications
}

\author{
P. M. García ${ }^{1}$, V. Moreno ${ }^{1}$, O. Azurza ${ }^{1}$, I. Arrambide $^{1}$ \\ Department of Electrical Engineering \\ University of the Basque Country \\ ${ }^{1}$ E.U.P., Plaza Europa 1, 28018 Donostia-San Sebastián (Spain)
}

Phone: +34943017 234, fax number: +34 943017 130, e-mail: pedromaria.garcia@ehu.es, vicente.moreno@ehu.es, olatz.azurza@ehu.es, inaki.arrambide@ehu.es

\begin{abstract}
.
Among the renewable energies, wind power has reached undoubtedly the greatest degree of maturity, although such maturity is based on the development of large-scale installations using larger machines every time. In recent years interest has grown in small wind generators, which allow access to this type of energy to small farms and to areas with difficult access. In this work, is performed the study of a permanent magnet synchronous generator (PMSG) using finite elements for such small applications. Various tests have been carried out to simulate no-load and short circuit conditions at different speeds in order to obtain data from these trials about their future behaviour.
\end{abstract}

\section{Key words}

Finite Elements, PMSG, Outer-rotor, Wind Energy.

\section{Introduction}

Several factors have promoted the development of renewable energy in recent years, among them, and probably as the most important, we could mention on the one hand, the need of reducing $\mathrm{CO}_{2}$ emissions causing greenhouse effect collected in international agreements like the Kyoto Protocol and, on the other hand, the problems of using nuclear energy [1] revealed by accidents such as Chernobyl and, more recently, Fukushima.

Among renewable energies, wind power has probably been the one that has most developed in recent decades due to the high availability of wind and the degree of maturity reached by this technology. The trend at industry levels is to create even larger generators every time, being able to focus the size of the currently installed generators from 5 to $7 \mathrm{MW}[1-3]$.

In contrast, smaller-scale generators may be an appropriate solution for remote areas such as islands, mountains and rural areas [4]. The American Wind Energy Association (AWEA) defines small wind generators as those whose power reaches up to $100 \mathrm{~kW}$, producing an increase in the U.S. market of $15 \%$ in 2009 [5].

This paper describes the study of a PMSG for its use in a small wind generator of about $11 \mathrm{~kW}$ power. By means of a finite element model, we simulate various tests on the machine, in order to predict the future behaviour of the machine.

\section{The analyzed machine}

The machine analyzed in this paper, is a small outer-rotor generator with magnets on the surface, the stator has a double layer lap winding with skewed slots. Table I shows some of the main design parameters.

TABLE I. Details of the analyzed machine

\begin{tabular}{|l|c|}
\hline Number of poles & 24 \\
\hline Number of stator slots & 72 \\
\hline Rotor outside diameter $(\mathrm{mm})$ & 364 \\
\hline Rotor inner diameter $(\mathrm{mm})$ & 339 \\
\hline Stator outer diameter $(\mathrm{mm})$ & 327 \\
\hline Permanent magnet material & $\mathrm{NdFeB}$ \\
\hline Thickness of the magnet $(\mathrm{mm})$ & 5 \\
\hline Minimun air gap $(\mathrm{mm})$ & 1 \\
\hline Relative permeability & 1.22 \\
\hline Remanent flux density $(\mathrm{T})$ & 1.2 \\
\hline
\end{tabular}

Figure 1 shows a detail of the geometry of the machine on the angle occupied by one of its magnets. It can be seen both the geometry of the stator slots with tooth structure of constant width and a slot opening of $3 \mathrm{~mm}$, such as the one used in the magnet which, having no radial development, generates a variable air gap with a minimum value of $1 \mathrm{~mm}$ in the symmetry axis. 


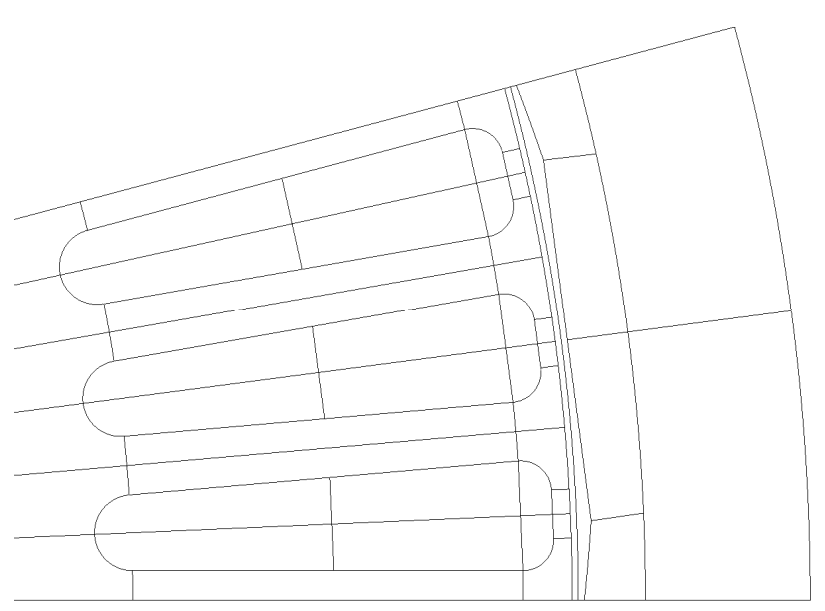

Fig 1. Details of the analyzed machine

\section{The developed models}

For the study finite element software FLUX-V-10.3 has been used. Initially a 2D model has been developed, from which and using the FLUX-SKEWED module, perform a more accurate model of the machine. FLUX-SKEWED module allows to take into account the inclination of the slot machine breaking down into several sections, the model obtained this way is more accurate than the one achieved with an application in $2 \mathrm{D}$, but without the complexity of 3D models.

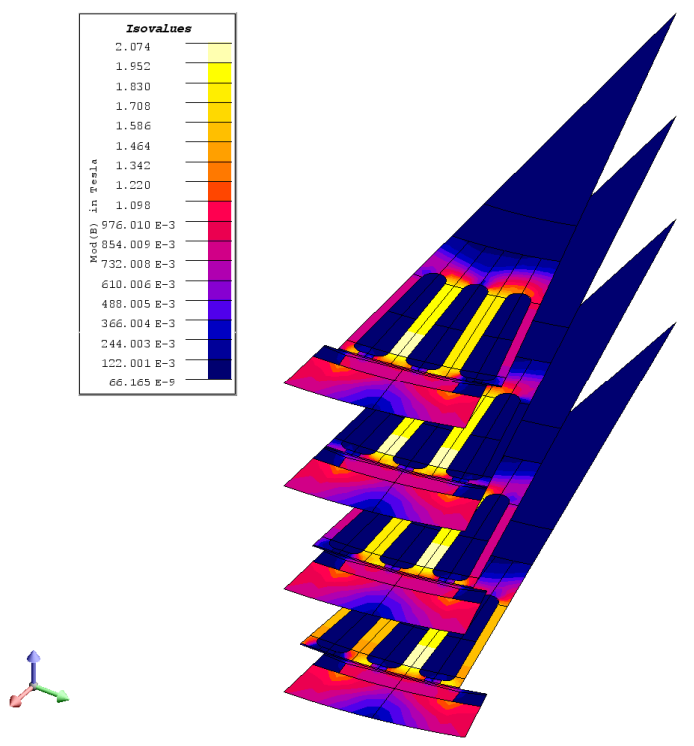

Fig 2. Magnetic flux density for a given position.

In regard to the geometry of the machine, and given the symmetries, a model that includes the angle of a pair of poles has been used. A detail of the model is shown in Figure 2, it shows the machine broken down into 5 sections, in which the distribution of magnetic flux for a given position is simulated.

In addition to the model of the machine geometry, for some of the simulations a model of the electrical circuit has been made (Fig. 3). This model includes data on the number of conductors, its resistance and so on. The different load conditions of the machine can be simulated by including in the elctrical circuit different resistive, inductive or capacitive elements. This circuit can also take into account the effect of the end-winding not represented in the geometrical model of the machine.

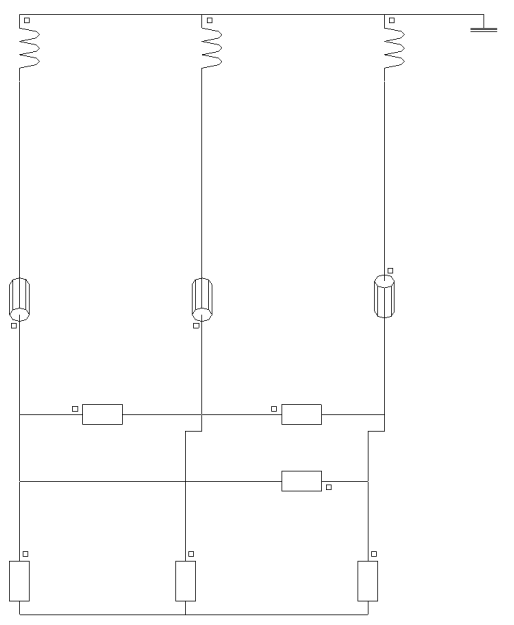

Fig 3. Electrical circuit for the model.

\section{Performed Tests}

Based on previous models, several tests have been simulated for the machine from which data will be obtained about their future behaviour. Some of these tests are the following:

- Calculation of Cogging Torque.

- No-load characteristic.

- Short-circuit characteristic.

\section{Cogging Torque}

Cogging torque, is the result of the interaction (magnetic attraction) between the magnetic flux from the magnets and stator geometry, producing a variable reluctance related with the angular position of the rotor. This torque, overlaps the generator load torque causing not only stress and vibration, but also an absence of power delivery at small wind speeds [6]. Cogging torque can be expressed mathematically by the following equation [7], [8]:

$$
T_{\operatorname{cog}}=-\frac{1}{2} \phi_{g}^{2} \frac{d \mathfrak{R}}{d \theta}
$$

where $\Phi_{g}$ is the magnetic flux density, $\mathfrak{R}$ is the air-gap reluctance and $\theta$ the rotor angular position.

Since reluctance varies periodically, it can also be expressed as a Fourier series by the following expression [7], [9], [10]:

$$
T_{\operatorname{cog}}=\sum_{k=1}^{\infty} T_{m k} \operatorname{sen}(m k \theta)
$$


where, $T_{\mathrm{mk}}$ is a coefficient which indicates the amplitude of each component of the series, $m$ is the least common multiple between the number of stator slots and pole number of the machine and $k$ is an integer. It can be proved that the number of cogging torque cycles per revolution of the rotor is equal to $m$.

Given the cyclical nature of cogging torque is not necessary to study it for a full rotation of rotor, restrigting the study to smaller angles, for example, the-stator slot pitch angle. The number of periods of cogging torque during rotation of one slot pitch $(N)$, can be determined easily using the expression showed below [11], [12]:

$$
N=\frac{2 p}{G C D(2 p, Q)}
$$

where $G C D$ is the maximum common divisor between number of poles $(2 p)$ and slot number $(Q)$. In general,we can assume that, increasing the number of cycles of the cogging torque, the maximum value for this will be lower.

Table II shows number of stator slots (Q), number of poles, number of slots per pole and phase (q), number of cogging torque cycles per revolution of the rotor $(\mathrm{m})$ and number of cycles per stator slot pitch $(\mathrm{N})$ of the analized machine.

TABLE II. Number of cycles of cogging torque

\begin{tabular}{|c|c|c|c|c|}
\hline$Q$ & $2 p$ & $q$ & $m$ & $N$ \\
\hline 72 & 24 & 1 & 72 & 1 \\
\hline
\end{tabular}

Figure 3 shows the cogging torque calculated using the initial 2D model of the machine, the figure shows the 4 cycles of this couple in the corner occupied by two slots.

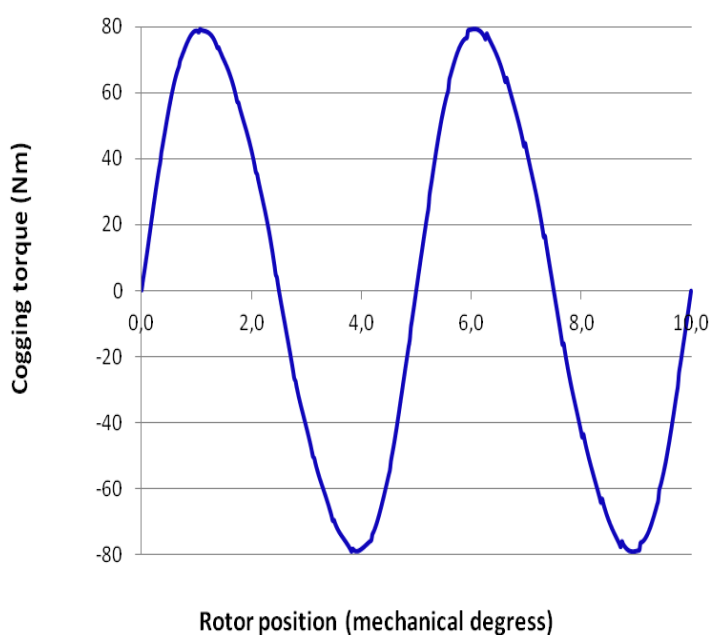

Fig. 3.Cogging torque using a 2D model.

Several methods [6-10] have been proposed to reduce cogging torque, in the case of the machine studied, this has the stator slots skewed, which requires, for its proper study, to use a more accurated model than the 2D model. Figure 4 shows cogging torque calculated from the full model (FLUX-SKEW) and taking into account the slot inclination.

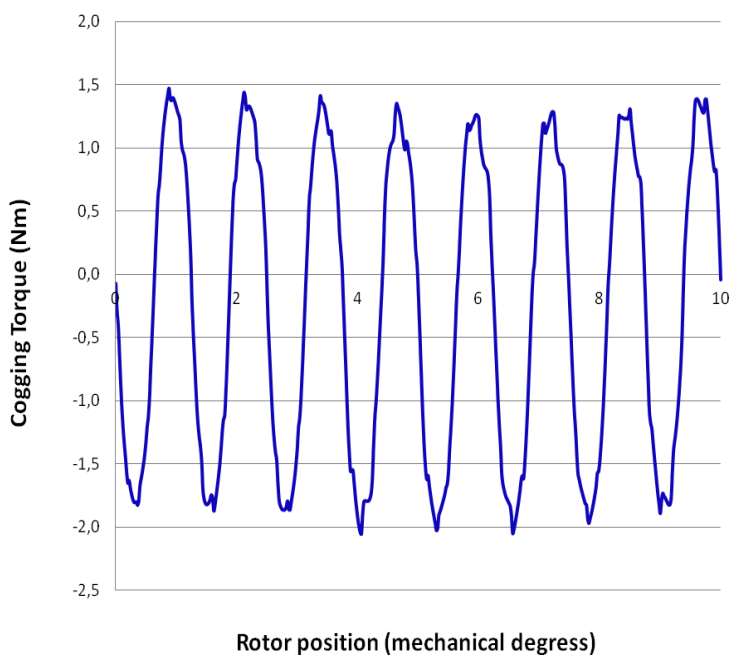

Fig. 4 Cogging torque taking into account the spot inclination.

The graph shows, like it happened in the figure 3, the angle occupied by two stator slots. The comparison between both graphs allows to check that the use of skewed slots, although not completely eliminating cogging torque, it does significantly reduce its values.

\section{No-load characteristic}

In a conventional synchronous machine with field winding this feature relates the value of the field current to the electromotive force (EMF) of the machine in its operation as a generator without load current. In the permanent magnet machines, the incapacity to regulate the current field makes this feature in a no load operation point for a given speed. Mathematically, we can express the value of this EMF as [13]:

$$
E_{f}=\pi \sqrt{2} f N_{1} K w_{1} \phi_{f}
$$

Where $N_{l}$ is the number of turns per phase, $f$ the frequency, $K w_{l}$ winding factor, $\Phi_{f}$ magnetic excitation flux.

Figure 5 shows the EMF of the tested machine to a rated speed of $50 \mathrm{rpm}(10 \mathrm{~Hz})$. Besides the graphical representation, some of the main calculation values obtained from the simulation of the no load operation are as follows:

$$
\begin{array}{lc}
\text { Mean values: } & -0,000 \\
\text { Rectified mean values: } & 105,4352 \\
\text { Rms values: } & 117,4383
\end{array}
$$

Equally interesting is to know the harmonic content of the EMF generated by the $\mathrm{m}$ achine, the program allows to know this content by applying to the previously calculated waveform an analysis by fast Fourier transform (FFT). 
$\operatorname{EMF}(\mathrm{V})$

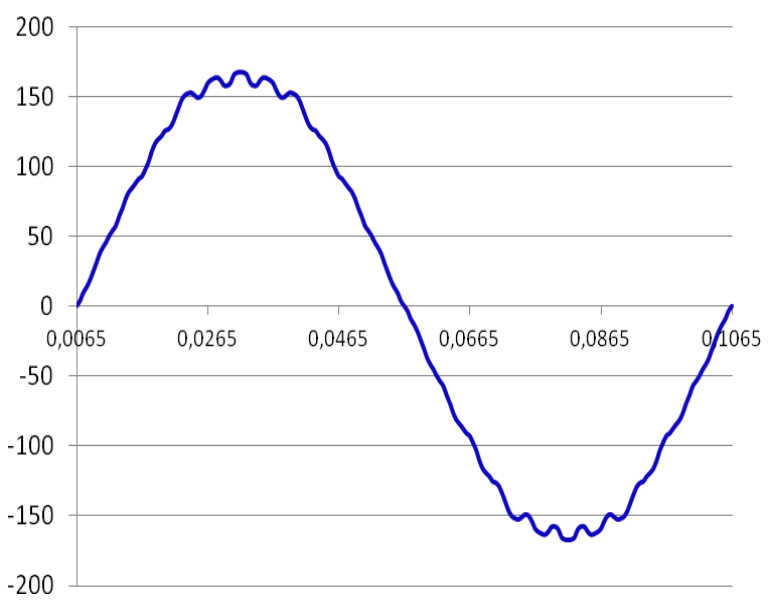

Fig. 5. No load EMF for $50 \mathrm{rpm}$.

Figure 6 shows this analysis for the voltage waveform shown before in which we can see the low harmonic content of the same.

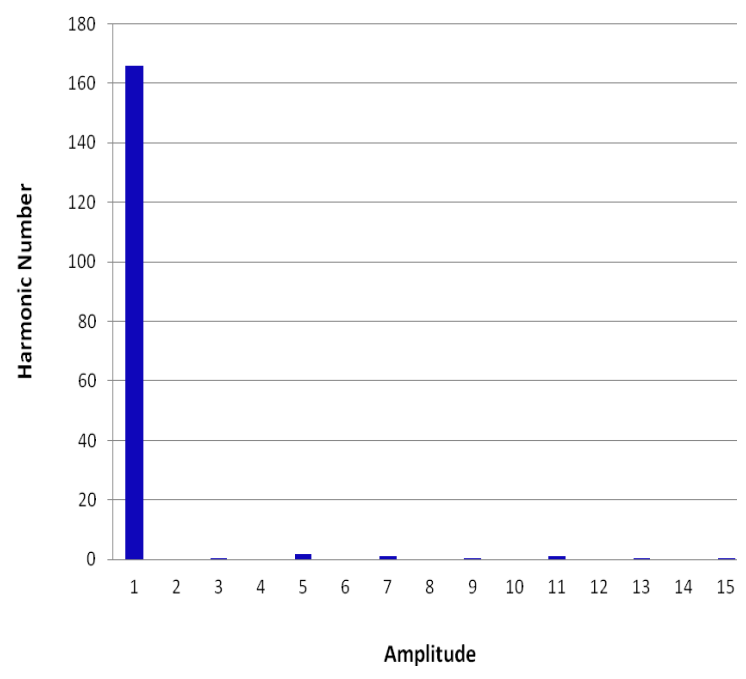

Fig. 6. FFT for the calculated EMF.

\section{Short-circuit characteristic}

As in the previous case, this feature, applied to a PMSG, becomes in a short circuit point, defined as the operating status of the machine in short-circuit permanent situation, that is, once transient phenomena have disappeared from it.

Regarding the model, in order to simulate the short circuit situation, the electrical model must be modified of to suit to the load situation of a short circuit.

Figure 7 shows the evolution of a cycle of the short circuit current of the machine for a similar speed that the used in the no-load characteristic $(50 \mathrm{rpm}-10 \mathrm{~Hz})$.

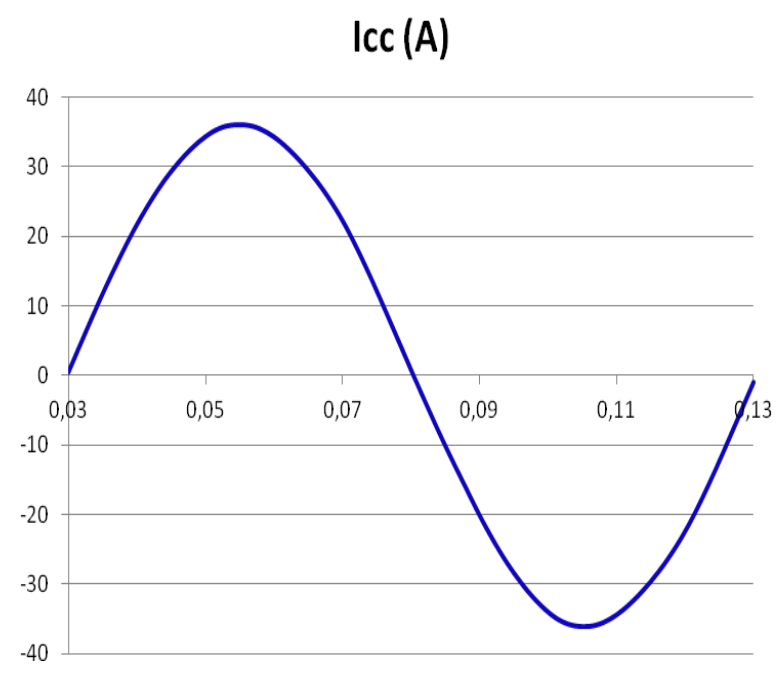

Fig. 7. Short circuit current for $50 \mathrm{rpm}$.

Numerically, some of the values obtained from the simulation of short circuit condition are:
Mean values:
0,6499
Rectified mean values:
22,6494
Rms values:
25,1243

In the short circuit situation, besides current, have also been calculated braking torques generated by the machine, for, from these values, to study possible support systems both electric braking (braking resistors), and mechanical. Figure 8 shows the braking torque calculated for a short circuit developed at a speed of $50 \mathrm{rpm}$.

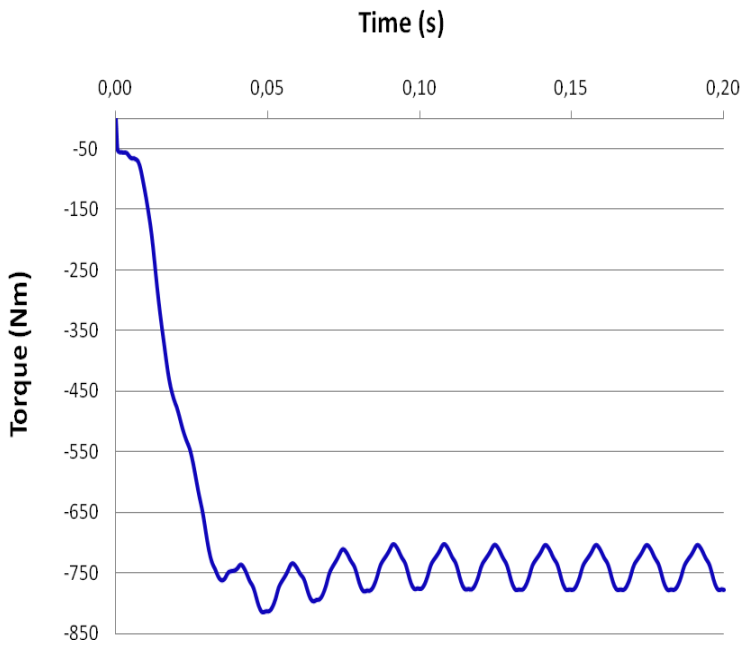

Fig. 8. Braking torque evolution in short-circuit situation.

Direct and quadrature axis reactances $\left(X_{d}, X_{q}\right)$ and phasor diagram of the machine

The no-load and short-circuit characteristics are two of the tests collected in EN 60034-4 to determinate the magnitudes of synchronous machines. In this standard, the calculation of the direct axis reactance $\left(X_{d}\right)$ it is 
proposed from no-load EMF values, and short-circuit current obtained for a given value of field current. In the case of permanent magnet machines, given the impossibility to regulate the field current, the value of this reactance can be calculated for a given speed and frequency, from EMF values and calculated short-circuit current.

As for the quadrature axis reactance $\left(X_{q}\right)$, given the geometry of the machine, with magnets on the surface, their value can be considered similar to that found for the case of $X_{d}$, could be said then:

$$
X_{q} \approx X_{d}=\frac{E_{f}}{I_{s c}}
$$

Using these reactances, it is possible to trace the phasor diagrams of the machine based on the equation (6) that describes its operation as a generator [13]:

$$
E_{f}=V_{1}+I_{a d}\left(R_{1}+j X_{d}\right)+I_{a q}\left(R_{1}+j X_{q}\right)
$$

According to the equation expresed above the phasor diagram of the machine would be as shown in Figure 9:

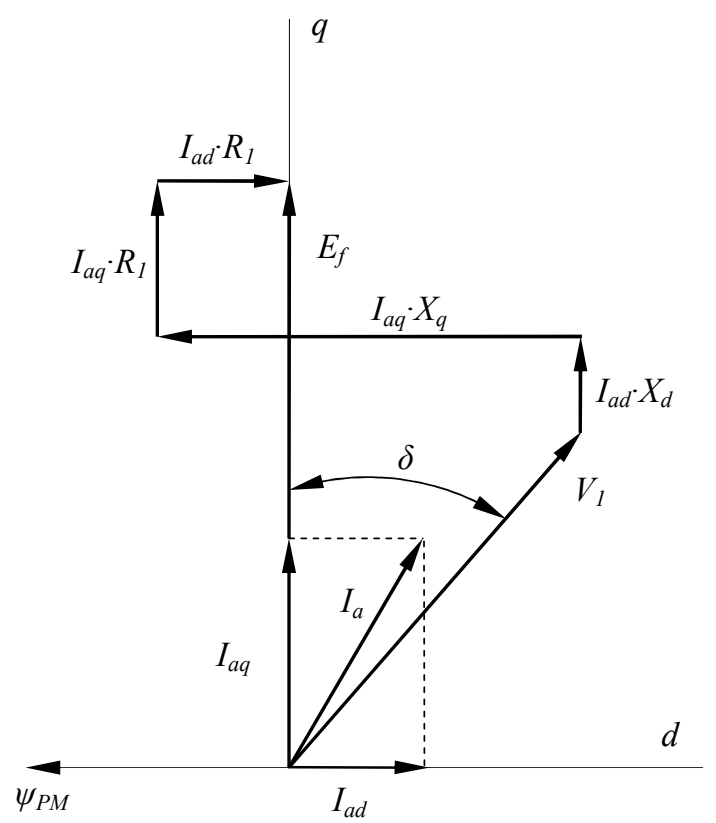

Fig. 9. Phasor diagram of the synchronous generador.

Where $E_{f}$ is the no-load EMF, $V_{l}$ is the imput voltage and $\delta$ is the torque angle of the machine for a given load state

In this diagram, the armature current $\left(I_{a}\right)$ appears decomposed into its components of direct and quadrature axis $\left(I_{a d}, I_{a q}\right)$. Some expressions for these currents can be calculated from the projections of the voltage $V_{l}$ on the $d$ and $q$ axis.

$$
V_{1} \operatorname{sen} \delta=I_{a q} X_{q}-I_{a d} R_{1}
$$

$$
V_{1} \cos \delta=E_{f}-I_{a d} X_{d}-I_{a q} R_{1}
$$

Developing the equations (7) and (8), is possible to obtain some expressions for the currents $I_{a d}, I_{a q}$, as shown in (9) and (10).

$$
\begin{gathered}
I_{a d}=\frac{X_{d}\left(E_{f}-V_{1} \cos \delta\right)-R_{1} V_{1} \operatorname{sen} \delta}{X_{d} X_{q}+R_{1}^{2}} \\
I_{a q}=\frac{R_{1}\left(E_{f}-V_{1} \cos \delta\right)+X_{d} V_{1} \operatorname{sen} \delta}{X_{d} X_{q}+R_{1}^{2}}
\end{gathered}
$$

These last expressions allow to calculate the components of the armature current on the $d$ and $q$ axis according to $V_{l}, E_{f}, X_{d}, X_{q}, \delta$ y $R_{l}$.

\section{Conclusions}

This paper has developed a model of PMSG by using finite element based software. From an initial model in 2D, a more accurate model has been developed, without reaching the complexity of 3D models, that allows to take into account the skewed-slots which is especially important when calculating the cogging torque of the machine. The model takes into account both the geometry and the electrical model of the winding of the machine being able to simulate two typical laboratory tests such as the no-load and the short-circuit, from which some interesting facts are obtained such as the harmonic content of generated EMF or the synchronous reactances of the machine.

The performed simulations and the obtained results show the utility of finite element method as a design tool for these machines, allowing to obtain results and predictions about future behaviour of these machines from the design stages.

\section{Acknowledgements}

The completion of this work and the contrast of the exposed results have been possible thanks to the collaboration of the staff of OBEKI plant in the town of Ibarra (Gipuzkoa - Spain).

\section{References}

[1] M. Dolores Esteban, J. Javier Diez, José S. Lopez, Vicente Negro, "Why Offshore Wind Energy?", Renewable Energy, 36 (2011), pp 444-450

[2] Simon-Philipe Breton, Geir Moe, "Status, Plans and Technologies for Offshore Wind Turbines in Europe and North America", Renewable Energy, 34 (2009), pp 646654.

[3] John K. Kaldellis, D. Zafirakis, "The Wind Energy (r)evolution: A Short Review of a Long History", Renewable Energy, 36 (2011), pp 1887-1901.

[4] Nguyen Thanh Hai, Suk-Ho Jang, Hong-Geuk Park, DongChoon Lee, "Sensorless control of PM synchronous generators for micro wind turbines", 2nd IEEE 
International Power and Energy Conference (2008), p 936941.

[5] M. Mañana, "Small Wind Energy Systems. State of the Art and New Challenges", ICREPQ'11 (invited Paper), Las Palmas de Gran Canaria, Spain, Apr. 2011.

[6] T. Tudorache, L. Melcescu, M. Popescu, "Methods for Cogging Torque Reduction of Directly Driven PM Wind Generators", 12th International Conference on Optimization of Electrical and Electronic Equipment, (OPTIM 2010).

[7] L. Dosiek, P. Pillay, "Cogging torque reduction in permanent magnet machines", IEEE Trans. Industry Application, vol. 43, no. 6, pp. 1656 - 1571, 2007.

[8] D. A. Gonzalez, J. A. Tapia, A. Letelier, "Desing Consideration to Reduce Cogging Torque in Axial Flux Permanent-Magnet Machines", IEEE Trans. On Magnetics, vol. 43, no. 8, pp. 3435 - 3440, 2007.

[9] Z. Q. Zhu, "Influence of Design Parameters on Cogging Torque in Permanent Magnet Machines". IEEE Trans. Energy Conversion, vol. 15, no. 4, pp 407-412, 2000.

[10] Z. Q. Zhu, S. Ruangsinchaiwanich, and D. Howe, "Synthesis of cogging-torque waveform form analysis of a single stator slot", IEEE Trans. Industry Applications, vol. 42, no. 3, pp. 650-657, 2006.

[11] M. S. Islam, S. Mir, T. Sebastian, "Issues in Reducing the Cogging Torque of Mass-Produced Permanent-Magnet Brushless DC Motors". IEEE Trans. Industry Applications, vol. 40, no. 3, pp 813-820, 2004.

[12] N. Bianchi, S. Bolognani. "Reducing Torque Ripple in PM Synchronous Motors by Pole-Shifting". ICEM 2000, pp 1222-1226.

[13] J. F. Gieras, M. Wing, "Permanent Magnet Motor Technology. Deisng and Applications". Marcel Dekker 2002. ISBN: 0-8247-0739-7.

[14] UNE-EN 60034 part 4: "Methods for determining synchronous machine quantities from test". 